\title{
New Tools for Ligand Refinement and Validation in Coot and CCP4
}

\author{
Paul Emsley, MRC Laboratory of Molecular Biology, Cambridge, UK
}

New tools for handling ligands have recently been added to Coot $[1,2,3]$ and the CCP4 Suite $[4,5]$. These tools include depiction of protein-ligand interactions (Figure 1), ligand editing and ligand dictionary generation.

Additionally, both Coot and AceDRG have been updated to facilitate the generation of covalent link geometry dictionaries, representation in Virtual Reality and an updated tool for N-linked glycan model building (Figure 2) [6].

These features will be showcased, with a particular emphasis on the description, generation and validation of links.

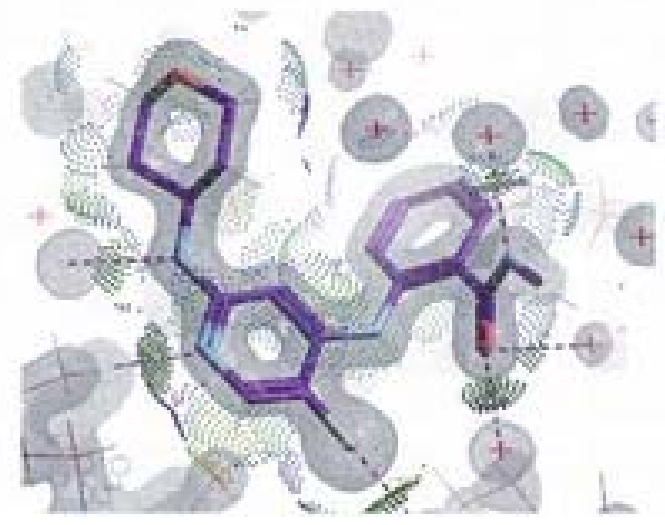

Figure 1

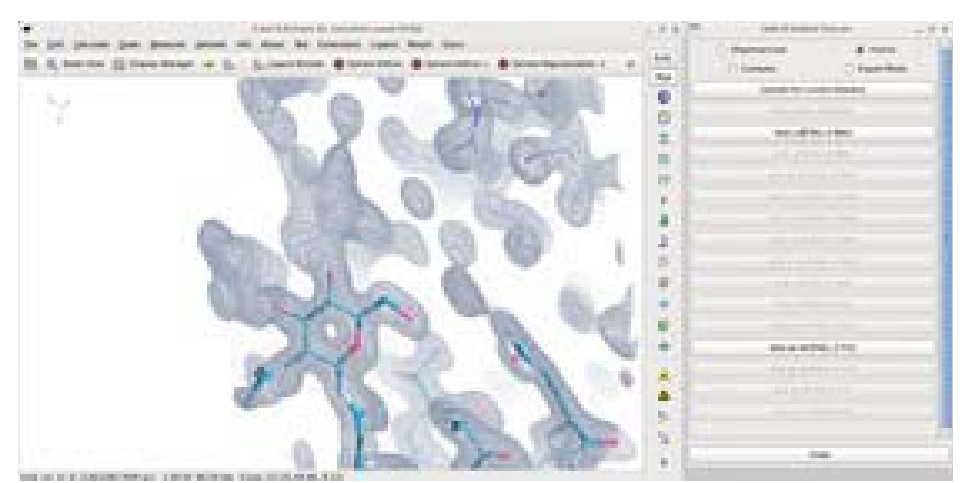

Figure 2

[1] "Features and Development of Coot" Emsley P, Lohkamp B, Scott W, Cowtan K, (2010) Acta Cryst. D. 66, 486-501

[2] "Handling ligands with Coot" Debreczeni JE, Emsley P (2012) Acta Cryst. D, 68, 425-430

[3] "Tools for ligand validation in Coot" Emsley P (2017) Acta Cryst. (2017). D73, 203-210

[4] "Validation and extraction of molecular-geometry information from small-molecule databases" Long F, Nicholls, RA, Emsley P, Grazulis S , Andrius M, Vaitkus A and Murshudov GN (2017) Acta Cryst D. 73(2) 102-111.

[5] "AceDRG: a stereochemical description generator for ligands" Long F, Nicholls RA, Emsley P, Grazulis S, Merkys A, Vaitkus A, and Murshudov GN (2017) Acta Cryst D. 73(2) 112-122.

[6] "Structural Analysis of Glycoproteins: Building N-linked Glycans with Coot" Emsley P and Crispin M (2018) Acta Cryst D.74, 256-263. 